\title{
Kısa Analiz Verileri Kullanılarak Biyokütlenin Üst Isı Değerinin Hesaplanması
}

\author{
*Neslihan DURANAY(0000-0001-7259-1864), Melek YILGIN(0000-0002-4177-8025) \\ Fırat Üniversitesi, Mühendislik Fakültesi, Kimya Mühendisliği Bölümü, ELAZIĞ \\ nduranay@firat.edu.tr, myilgin@firat.edu.tr
}

Geliş Tarihi: 11.10.2017

Kabul Tarihi: 31.05 .2018

$\ddot{O z z}$

Biyokütle küresel 1sınmaya katkıda bulunmayan, alternatif enerji kaynaklarından biridir. Biyokütlenin yakıt olarak kullanımının, fosil yakıtlardan kaynaklanan sorunlara çözüm olacağı düşünülmektedir. Biyokütle ile çalışan bir tesis tasarlanacağı zaman ısıl değerinin belirlenmesi gerekmektedir. Çünkü 1sıl değer tesisin kapasitesini belirlemede en önemli parametredir. $\mathrm{Bu}$ çalışmada bölgemizde fazla miktarda bulunan on farklı biyokütlenin kısa analiz verileri kullanılarak üst ısı değerleri (ÜID) hesaplandı. Hesaplamalarda dört farklı eşitlik kullanıldı. Eşitlik E1, E2, E3, E4 sırasıyla biyokütlenin kül, uçucu madde, kül ve uçucu madde, uçucu madde ve sabit karbon içeriklerini dikkate alarak ÜID’ni tahmin etmek için kullanıld1. Ayrıca, adyabatik kalorimetre bombası kullanılarak numunelerin ÜID’leri deneysel olarak belirlendi. Deneysel ve tahmin edilen ÜID’leri her bir numune için karşılaştırıldı ve standart sapmanın 0.5 ila $1.87 \mathrm{~kJ} / \mathrm{g}$ aralığında değiştiği tespit edildi. Tahmin edilen değerler, deneysel değerlere karşı grafiğe geçirildiğinde $\mathrm{R}^{2}$ değerlerinin yakın olduğu belirlendi. Ayrıca hesaplanan ve deneysel olarak belirlenen üst ısı değerlerinin biyokütlenin uçucu madde ve kül oranlarından etkilendiği tespit edildi.

Anahtar Kelimeler: Biyokütle, üst 1sı değeri, kısa analiz.

\section{Estimation of Higher Heating Value of Biomass Using Proximate Analysis Data}

\author{
Neslihan DURANAY*, Melek YILGIN \\ Frrat Üniversitesi, Mühendislik Fakültesi, Kimya Mühendisliği Bölümü, ELAZIĞ \\ nduranay@firat.edu.tr,myilgin@firat.edu.tr
}

\begin{abstract}
Biomass is one of the alternative energy sources that do not contribute to global warming. The use of biomass as fuel is thought to be a solution to problems arising from fossil fuels. When designed a plant that works with biomass, the calorific value should be determined. Because the calorific value is the most important parameter in determining the capacity of the plant. In this study, higher heating value (HHV) were estimated using proximate analysis data of ten different biomass. Four different equations were used in estimations. The equations are used to estimate the HHV by considering the contents of the ash (E1), volatile matter (E2), ash and volatile matter (E3) and volatile matter and fixed carbon (E4) of the biomass. In addition, the HHV's of the samples were experimentally determined by using an adiabatic calorimeter bomb. The experimental and estimated HHV's were compared for each sample and the standard deviations were found to vary from 0.5 to $1.87 \mathrm{~kJ} / \mathrm{g}$. When estimated values were plotted against experimental values, it was determined that $\mathrm{R}^{2}$ values were close to each other. In addition, it was detected that estimated and experimentally determined HHV's were affected from the volatile matter and ash ratios of the biomass.
\end{abstract}

Keywords: Biomass, higher heating value, proximate analysis

*Sorumlu Yazar: Fırat Üniversitesi, Mühendislik Fakültesi, Kimya Mühendisliği Bölümü, ELAZIĞ

nduranay@ firat.edu.tr

Doi: 10.21541/apjes.342951 


\section{GíRiș}

Enerji, sosyal ve ekonomik kalkınmanın ana kaynaklarından biridir. Son yüz yılda, dünyadaki enerji tüketimi yaklaşık 17 kat artmıştır [1,2]. Artan enerji ihtiyac1, toplumları ucuz, bol ve çevre üzerinde daha az etkiye sahip alternatif enerji kaynakları bulmaya yönlendirmiştir. Hızla tüketilen fosil yakıtlar, bu gereksinimleri karşılamaktan çok uzaktır. Bu yüzden, biyokütle bol miktarda, bulunması kolay, yenilenebilir ve sürdürülebilir bir enerji kaynağı olarak görülüyor [3]. Bu niteliklerin sonuncusu olan sürdürülebilirlik, uzun menzilli taşımalardan kaçınmak için yerel olarak tedarik edilen hammaddelerden yakıtların geliştirilmesi; gıda ve elyaf üretimi için kullanılan toprak ve su ile rekabet etmeyen; ve sera gazı emisyonlarını azaltması anlamına gelmektedir [4]. Bu yüzden biyolojik kütlenin sürdürülebilir bir enerji kaynağ1 olma potansiyeli, tüm dünyada önemli bir araştırma konusu olmuştur.

Biyokütlenin enerjiye biyolojik veya termokimyasal dönüşümünün verimini belirlemek için, biyokütlenin potansiyel enerji içeriği bilinmelidir [4]. Bir yakıtın 1sı değeri, alt 1s1 veya üst 1S1 değerinden biri kullanılarak verilir. Yakıtın üst 1sı değeri, yakıtın birim kütlesi tamamen yakıldığında normal suyun yoğunlaşma derecesini standart koşullar altında yanma ürünü olarak hesaplayan 1S1 miktarına eşittir. Yüksek üst 1sı değerine sahip yakıtlar yandığında yüksek enerji çıkışı elde edilir. $\mathrm{Bu}$ özellik biyokütle yakma sistemlerinin tasarımı ve işletilmesi açısından çok önemlidir.

Yakıt olarak ele alınan biyokütlenin üst 1sı değeri, bir reaktan ile ürünlerin entalpisi arasındaki değişikliklerin basit ve doğru bir ölçümü olan adyabatik bir oksijen bombası kalorimetresi kullanılarak deneysel olarak belirlenebilir. Basit olmasına rağmen, üst 1sı değerini deneysel olarak analiz etmek her zaman mümkün olmayabilir [5,6] . Literatürde kömür ve biyokütle için üst 1S1 değerini yakıtın elementel bileşimine $(\mathrm{C}, \mathrm{H}, \mathrm{N}, \mathrm{O}, \mathrm{S})$ dayandıran birçok model bulunmaktadır [5-9]. Yin [5] özellikle lignoselülozik bileşiklerden oluşan biyokütlelerin üst isı değerlerinin kısa ve elementel analiz verileri kullanılarak hesaplanması için doğrusal regresyonla iki denklem geliştirmiş ve bu denklemlerin üst 1sı değerinin hızlı hesaplanmasına katkıda bulunacağını belirtmiştir. Bununla birlikte, elementel analiz, masraflı ve zaman alıcı olabilir, bu nedenle araştırmacılar biyokütle gibi katı yakıtların üst 1sı değerini tahmin etmek için deneysel yöntemlere yönelmiştir [1-4,7-11]. Garcia ve ark [1] hem elementel hem de kısa analiz verilerini kullanarak üst isı değerlerini hesaplamışlar. Örneğin nem içeriğinin kullanılacak denklemin belirlenmesinde etkili olduğu ve kısa analiz verileri ile belirlenen üst isı değerlerinin daha iyi sonuç verdiğini belirtmişlerdir. Biyokütlenin isıl değerinin tahmininde kısa analiz verilerinin kullanılmasının en ucuz ve kolay yöntem olduğunu belirten Erol ve ark.[7] geliştirdikleri korelasyonların isıl değerin tahmininde kullanılabileceğini göstermişlerdir.
Uzun ve ark.[4] ise sadece k1sa analiz verileri kullanılarak biyokütlenin üst 1s1 değerinin doğru olarak tahmin edilmesinin, yenilenebilir yakıt üretimi için biyokütle ve biyokütle karışımlarının belirlenmesine yardımcı olacağını vurgulamışlardır. Üst 1sı değerini tahmin etmek için 131 biyokütle numunesi veri seti kullanarak bir yapay sinir ağ modeli oluşturmuşlardır. $\mathrm{Bu}$ tür matematiksel modeller, katı yakıtın nem, uçucu madde, sabit karbon ve külünün ağırlık yüzdelerine (ağırlıkça\%) dayanmaktadır. Katı bir yakıtın nem, uçucu madde, kül ve sabit karbon içeriğinin belirlendiği kısa analizi basit bir şekilde [6] ve daha ayrıntılı analizlerden ucuz ve kısa sürede yapılabilir. Böylece kısa analiz gibi basit faktörlere dayanılarak üst 1sı değeri hızlı bir şekilde hesaplanır ve 1sı verimi yüksek karışımlar elde edilir. Bir yakıt veya yakıt karışımına ait üst 1S1 değerinin hılı tahmin edebilme özelliği, biyokütlenin ön işlenmesi gerekliliğini belirler.

Sunulan çalışmada, farklı kaynaklardan (tarım, orman ve gıda endüstrisi) elde edilen ve bölgemizde önemli potansiyele sahip lignoselülozik yapıdaki atık biyokütlelerin sadece kısa analiz verileri kullanılarak üst 1sı değerlerinin belirlenmesi amaçlandı. Kısa analiz verileri ile yapılacak hesaplama için literatürde verilen dört farklı denklem kullanıldı. Denklemler, üst 1sı değerinin hesaplamasında biyokütlenin içerdiği külün (E1), uçucu maddenin (E2), kül ile uçucu maddenin birlikte (E3) ve sabit karbon ile uçucu maddenin birlikte (E4) etkisini belirlemek üzere seçildi [2,5,12]. Hesaplanan üst 1s1 değerleri biyokütle numunelerinin literatürde verilen ve adyabatik oksijen kalorimetresi kullanılarak tespit edilen deneysel değerleri ile karşılaştırıldı.

\section{MALZEME VE YÖNTEM}

\section{1. Örneklerin Hazırlanması}

$\mathrm{Bu}$ çalışmada on biyokütle örneği kullanıldı. Biyokütle örnekleri bölgemizde kolayca elde edilebilen tarımsal, orman ve gida endüstrisi atıklarından seçildi. $\mathrm{Bu}$ çalışmada; ceviz kabuğu, fındık kabuğu, kayısı çekirdeği, pamuk kozası, ay çekirdeği kabuğu, şarap fabrikası atığ1, mobilya fabrikası atık tozu, meşe talaşı, çam kozalağı ve çam talaşı kullanıldı.

Nemli olan numuneler laboratuvar ortamında kurutuldu ve mobilya tozu dışındaki biyokütleler parçalayıcı kullanılarak öğütüldü ve elendi. Elenen numuneler kilitli poşetlerde nem almayacak şekilde muhafaza edildi. Elenen numunelerin $75 \mu \mathrm{m}$ (100 mesh elek altı) parçacık boyutundaki taneler çalışmada kullanıldı.

\subsection{Kısa (Proximate) Analiz}

Deneysel çalışmalarda kullanılan numunelerin öncelikle nem tayini yapıld1. Bu tayin $105^{\circ} \mathrm{C}$ 'de Mettler LJ16 nem tayin cihazında ( $\pm \% 0.01$ hassasiyet $)$ gerçekleştirildi.Numunenin uçucu madde (UM) ve kül oranı ASTM standardına [13,14] göre belirlendi. Sabit 
karbon (SK) miktarı aşağıda verilen Eşitlik (1) ile hesaplandi.

$\% \mathrm{SK}=100-(\% \mathrm{UM}+\% \mathrm{Nem}+\% \mathrm{Kül})$

Deney verilerinin doğruluğunun kontrolü için, analizler birkaç kez tekrarlandı. $\pm \% 5$ 'den daha düşük sapma görülen paralel çalışmaların sonuçlarının ortalaması alındı.

\section{3. Üst Isı Değerinin (ÜID) Tayini}

Biyokütle örneklerinin deneysel olarak ÜID belirlemek için JULIUS PETERS IBERLIN adyabatik kalorimetresi kullanıldı. Analiz yapılırken kapsül, tel ve numunelerin tartımı yapıldı. Kapalı sistem içinde ağırlıkları bilinen örneklerin yanması sonucunda açığa çıkan 1S1, 1S1 sensörleri yardımıyla tespit edildi. Üst 1 sı değerleri kalorimetrenin kullanım kılavuzunda belirtilen aşağıdaki eşitlik ile hesapland.

ÜID $=\frac{\left(2370.18 \times \Delta \mathrm{T}-4713 \times \mathrm{m}_{\mathrm{kap}}-577.3 \times \mathrm{m}_{\text {tel }}\right)}{\mathrm{m}_{\text {numune }}}$

$\mathrm{Bu}$ eşitlikte; mkap;kapsül kütlesi $(\mathrm{g}), \mathrm{m}_{\text {tel }}$; yakma için kullanılan telin kütlesi $(\mathrm{g})$ ve $\mathrm{m}_{\text {numune; }}$ numune kütlesi $(\mathrm{g})$ olarak verilmektedir. ÜID'nin belirlendiği deneyler de birçok defa tekrarlandı ve sapması $\pm \% 5$ ' in altında olan değerlerin ortalaması alındı.
Ayrıca Tablo 1'de verilen eşitlikler kullanılarak biyokütle numunelerinin ÜID'leri hesapland.

Tablo 1. Kisa analiz verilerinden ÜID (kJ. $\left.\mathrm{g}^{-1}\right)$ hesaplamada kullanılan eşitlikler.

\begin{tabular}{|l|lc|}
\hline & \multicolumn{3}{|l|}{ Eşitlik } \\
\hline E1 & ÜID $=20.086-0.261 \times$ Kül & {$[2,12]$} \\
\hline E2 & ÜID $=-13.173+0.416 \times$ UM & {$[2,12]$} \\
\hline E3 & ÜID $=-2.057-0.092 \times$ Kül $+0.279 \times \mathrm{UM}[2,12]$ \\
\hline E4 & ÜID $=0.1905 \times \mathrm{UM}+0.2521 \times \mathrm{SK}$ & {$[2,5]$} \\
\hline
\end{tabular}

\section{BULGULAR VE TARTIŞMA}

Tablo 2'de on biyokütlenin kısa analiz sonuçları verilmektedir. Genel olarak uçucu madde yüzdesinin yüksek olduğu görülmektedir. En yüksek uçucu madde oranı çam talaşında tespit edildi. $\mathrm{Bu}$ durumun çamın reçineli bir biyokütle olmasından kaynaklandığ düşünülmektedir. En düşük uçucu madde oranı ise nem ve kül içeriği yüksek olan pamuk kozasında tespit edildi. Şarap fabrikası atığı ve pamuk kozasının kül içeriği biyokütle olarak oldukça yüksek bulunurken diğer biyokütlelerin beklenen sinırlar içerisinde olduğu belirlendi. Biyokütle örneklerinin sabit karbon oranlarının ise $\% 14$ ile $\% 20$ arasında olduğu tespit edildi.

Tablo 2 : Kisa analiz verileri.

\begin{tabular}{|l|c|c|c|c|}
\hline Numune & \% Nem & \%Uçucu Madde & \% Kül & \% Sabit Karbon* \\
\hline Ceviz kabuğu & 6.7 & 70.6 & 4.7 & 18.0 \\
\hline Şarap fabrikası atığ & 4.9 & 65.1 & 11.1 & 18.9 \\
\hline Mobilya atık tozu & 5.1 & 74.7 & 1.5 & 18.7 \\
\hline Meşe talaşı & 6.0 & 74.3 & 2.7 & 17.0 \\
\hline Fındık kabuğu & 6.4 & 69.1 & 7.3 & 17.2 \\
\hline Kayısı çekirdeği & 5.0 & 76.7 & 0.6 & 17.7 \\
\hline Pamuk kozası & 9.5 & 58.2 & 13.6 & 19.7 \\
\hline Çam kozalağ1 & 7.1 & 71.8 & 1.9 & 19.2 \\
\hline Çam talaş1 & 5.3 & 80.1 & 0.5 & 14.1 \\
\hline Ay çekirdeği kabuğu & 5.5 & 73.3 & 6.9 & 14.3 \\
\hline
\end{tabular}

*Farktan hesaplandi.

Denklemlerden hesaplanan ÜID'leri aynı tür biyokütleler için literatürde verilen ve deneysel olarak bulunan değerler ile Tablo 3'de karşılaştırılmaktadır. Hesaplanan ÜID'nin literatürde verilen ve deneysel olarak tespit edilenler ile uygunluk içinde olduğu belirlendi.

En yüksek ÜID çam talaşı için hesaplandı ve deneysel olarak bulunan değere oldukça yakın olduğu (ortalama \% 2.25 hata) tespit edildi. Bu durum çam talaşının reçineli yapısı ve dolayısıyla uçucu madde miktarının fazla olmasından kaynaklanmaktadır. Diğer taraftan en düşük üst 1S1 değeri, nem ve kül içeriği yüksek, uçucu madde oranı düşük olan pamuk kozasında elde edildi ve bu numunenin deneysel ısıl değeri de düşük bulundu. Her bir numunenin kisa analiz verilerinden hesaplanan ve deneysel olarak bulunan ÜID'nin standart sapması hesaplandı ve 0.5 ile $1.87 \mathrm{~kJ} / \mathrm{g}$ arasında değiştiği tespit edildi.

Meşe, çam kozalağı ve şarap fabrikası atığı için deneysel olarak tespit edilen ÜID'nin literatürde verilenlere [2] yakın olduğu görüldü. Diğer taraftan ceviz, findık ve kayısı çekirdeği kabuğu ile şarap fabrikası atığının 
hesaplanan ÜID'nin literatürle uygunluk gösterdiği tespit edildi. Şarap fabrikası atığının hesaplanan ÜID'nin hem literatür hem de deneysel olarak belirlenen ÜID ile uygunluk içinde olması, bileşiminin üretildiği bölgeye göre değişmediğini göstermektedir.

Tablo 3. Kısa analiz verilerinden hesaplanan üst 1sı değerleri

\begin{tabular}{|l|l|l|l|l|c|c|c|}
\cline { 2 - 5 } \multicolumn{1}{c|}{} & \multicolumn{9}{c|}{ Eşitlik No: } & \multicolumn{1}{c|}{} \\
\hline Numune & E1 & E2 & E3 & E4 & $\begin{array}{c}\text { Deneysel } \\
\text { ÜID (kJ/g) }\end{array}$ & $\begin{array}{c}\text { Standart } \\
\text { Sapma (kJ/g) }\end{array}$ & $\begin{array}{c}\text { iteratür [2] } \\
\text { ÜID (kJ/g) }\end{array}$ \\
\hline Ceviz kabuğu & 18.32 & 18.68 & 19.07 & 19.28 & 19.61 & 0.504 & 18.38 \\
\hline Şarap fabrikası atığ1 & 17.19 & 15.95 & 16.24 & 18.10 & 16.19 & 0.898 & 16.46 \\
\hline $\begin{array}{l}\text { Mobilya fabrikas1 } \\
\text { atık tozu }\end{array}$ & 19.68 & 20.02 & 20.06 & 19.89 & 17.73 & 0.978 & 18.80 \\
\hline Meşe talaş1 & 19.38 & 20.23 & 20.10 & 19.59 & 17.65 & 1.034 & 17.18 \\
\hline Fındık kabuğu & 18.19 & 18.24 & 18.33 & 19.11 & 17.00 & 0.755 & 18.87 \\
\hline Kayı11 çekirdeği & 19.93 & 20.81 & 20.68 & 20.01 & 17.19 & 1.470 & 19.59 \\
\hline Pamuk kozası & 16.54 & 14.99 & 15.58 & 17.60 & 12.64 & 1.866 & 16.54 \\
\hline Çam kozalağ1 & 19.59 & 19.65 & 19.78 & 19.87 & 18.84 & 0.528 & 18.63 \\
\hline Çam talaş1 & 19.35 & 22.35 & 21.72 & 19.81 & 20.35 & 1.274 & 18.50 \\
\hline Ay çekirdeği kabuğu & 18.28 & 19.61 & 19.29 & 18.61 & 18.96 & 0.528 & 18.00 \\
\hline
\end{tabular}
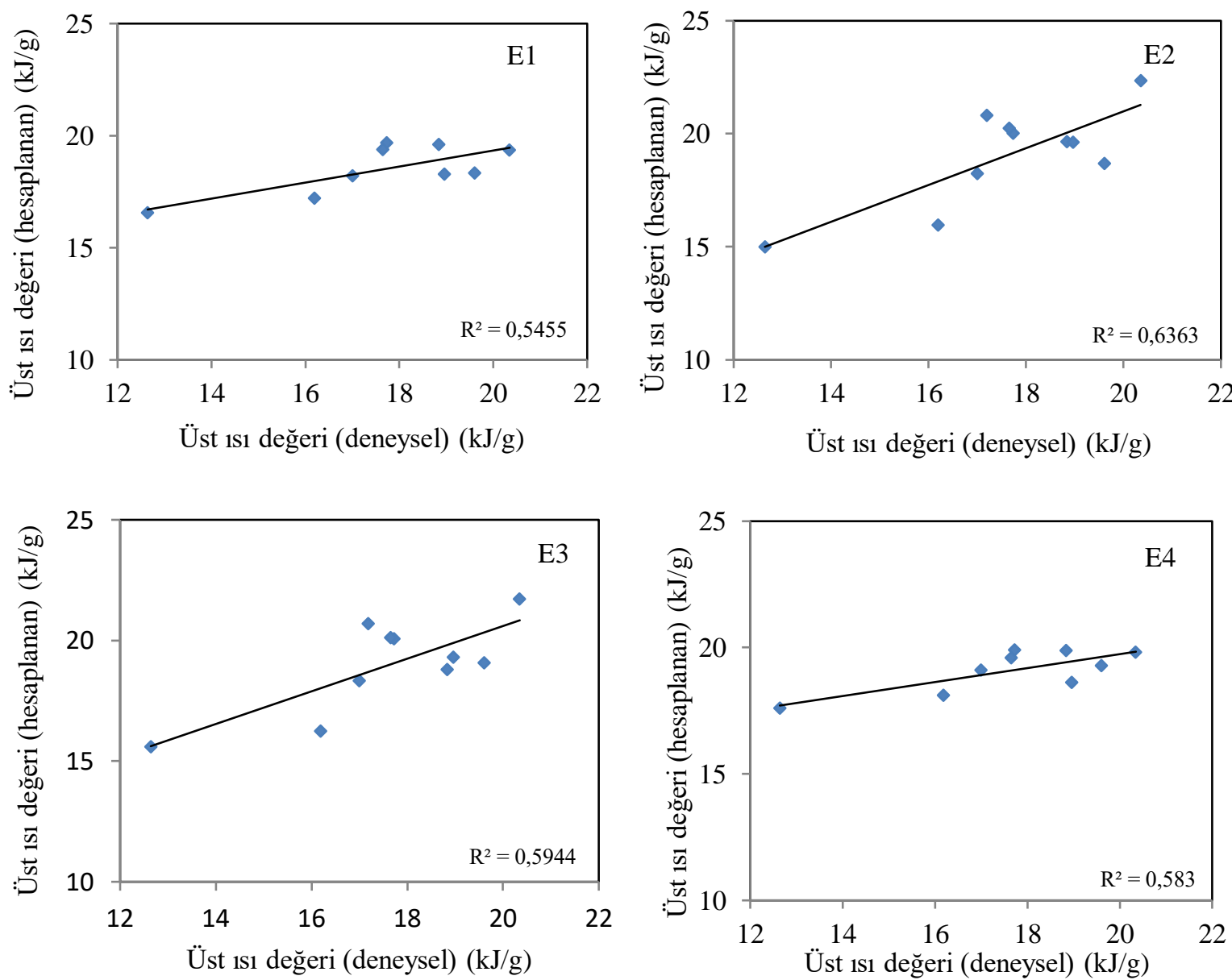

Şekil 1. Deneysel ve hesaplanan üst ısı değerleri arasındaki ilişki. 
Denklemlerden elde edilen ÜID'leri deneysel olarak belirlenenlere karşı grafiğe geçirildi ve $\mathrm{R}^{2}$ değerleri hesapland 1 (Şekill) ve birbirine yakın olduğu tespit edildi. $\mathrm{R}^{2}$ ve standart sapma değerleri birlikte ele alınırsa, bu çalışmada kullanılan denklemlerin, biyokütle örneklerinin kısa analiz verileri kullanılarak ÜID'nin hesaplanabileceği söylenebilir. Uçucu madde termal bozunumu ve tesis tasarımını etkileyen önemli bir bileşendir. Yüksek uçucu içeriği düşük sıcaklıklarda ateşlemeyi kolaylaştırır, bu da yüksek reaktiviteye neden olur ve yanma sürecini zenginleştirir [2]. Şekil 2'de biyokütlelerin dört farklı denklemden hesaplanan ve deneysel olarak belirlenen ÜID'nin uçucu madde konsantrasyonu ile değişimi verilmektedir. Biyokütlenin uçucu madde konsantrasyonu arttıkça üst 1Sı değerinin arttığı hem hesaplanan hem de deneysel değerlerde açıkça görülmektedir. Bu durumda bir biyokütlenin kısa analiz verilerinden ÜID tahmin edilecekse uçucu madde oranın tek başına yeterli olabileceği söylenebilir.

Sabit karbon yanmasından sonra kalan inorganik atıkları kül olarak tarif edebiliriz. Kül yanma teknolojisini belirlemede önemli parametrelerden biridir. Çünkü artan kül oranı biyokütleye oksijen difüzyonunu etkilediğinden oluşan yetersiz yanma ÜID’ni ve yanma verimini düşürür [2]. Şekil 3'de deneysel ve hesaplanan ÜID'nin biyokütlenin kül oranıyla değişimi verilmektedir. ÜID’nin artan kül miktarı ile azaldığı tespit edildi. Bu durum hem deneysel hem de hesaplanan isıl değerlerde görüldü. En yüksek oranda kül içeren pamuk kozası ve şarap fabrikası atığının ÜID'nin diğer numunelerden düşük olduğu, diğer taraftan kül içeriği en düşük olan çam talaşının deneysel ve hesaplanan ÜID’nin yüksek olduğu tespit edildi.

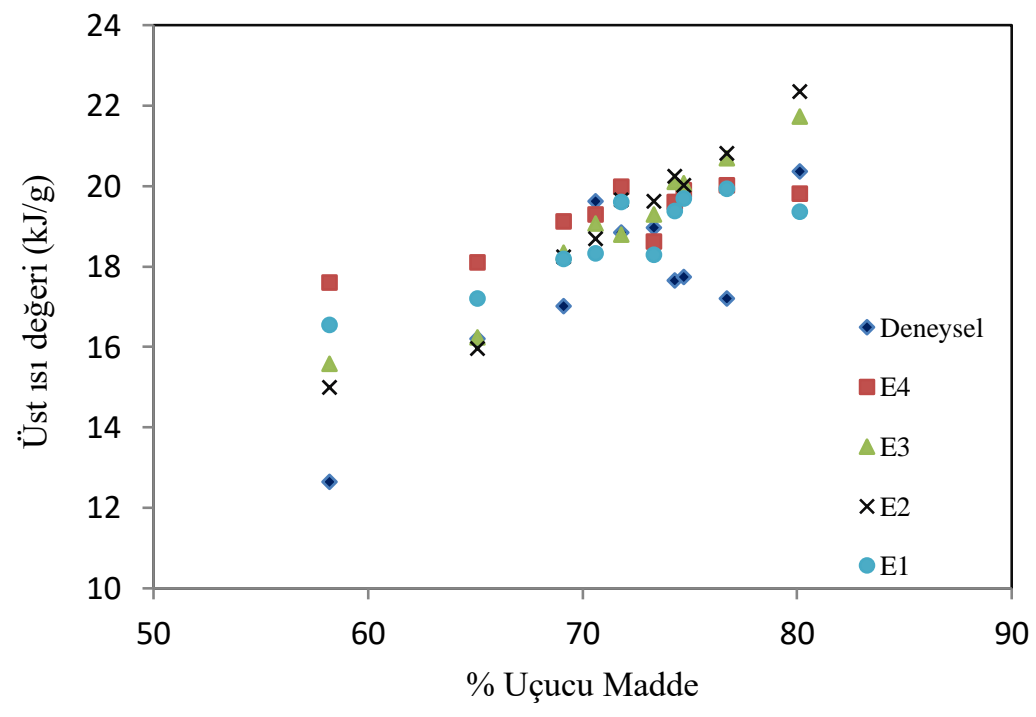

Şekil 2. Biyokütlenin uçucu madde içeriğinin üst 1sı değerine etkisi.

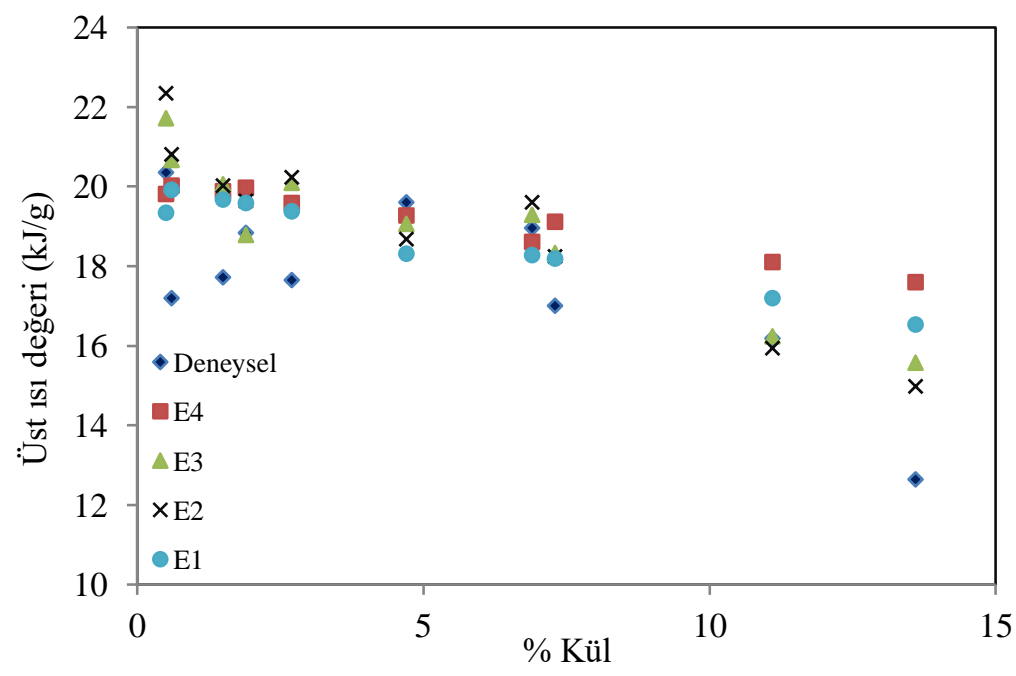

Şekil 3. Biyokütlenin kül içeriğinin üst ısı değerine etkisi. 


\section{SONUÇLAR}

$\mathrm{Bu}$ çalışmada araştırılan denklemlerin, biyokütle örneklerinin kısa analiz verileri kullanılarak ÜID'nin hesaplanabileceği tespit edildi. Her bir numunenin kısa analiz verilerinden belirlenen ÜID'nin standart sapmas1 hesaplandı ve 0.5 ile $1.87 \mathrm{~kJ} / \mathrm{g}$ arasında değiştiği ve $\mathrm{R}^{2}$ değerlerinin birbirine yakın olduğu tespit edildi.

Hesaplanan ÜID'nin literatürden alınan ve deneysel olarak tespit edilenler ile uygunluk içinde olduğu belirlendi.

Biyokütlenin uçucu madde içeriğinin yüksek olması 1S1 elde edilmesinde kullanımı için bir avantaj olacağ1 belirlendi. En yüksek 1sıl değer çam talaşı için hesaplandı ve deneysel olarak bulunan isı değeriyle oldukça yakın olduğu (ortalama \% 2.25 hata) tespit edildi.

Ayrıca kül oranının da biyokütlenin ısıl değeri üzerinde etkili olduğu açıkça görüldü. En düşük ÜID, kül içeriği yüksek olan pamuk kozasının deneysel ve hesaplanan isıl değerinde elde edildi.

Sonuç olarak enerji üretimi için biyokütlenin kullanılacağ1 sistemlerin tasarımı yapılırken, ÜID'nin kısa analiz verilerinden hızlı ve orijinal değerine yakın olarak elde edilebileceği tespit edildi.

\section{KAYNAKLAR}

[1] R. García, C. Pizarro, A.G. Lavín and J.L.Bueno, "Characterization of Spanish biomass wastes for energy use”, Bioresource Technol, vol.103, pp. 249-58, 2012.

[2] R. García, C.. Pizarro , A.G. Lavín, J.L. Bueno, "Spanish biofuels heating value estimation. Part II: Proximate analysis Data", Fuel, vol.117, pp. 1139-1147, 2014.

[3] E. Akkaya, "ANFIS based prediction model for biomass heating value using proximate analysis components", Fuel, vol.180, pp.687-693, 2016.
[4] H.Uzun, Z. Yıldı, J. L. Goldfarb, S. Ceylan, "Improved prediction of higher heating value of biomass using an artificial neural network model based on proximate analysis", Bioresource Technology, vol.234, pp.122-130, 2017.

[5] C.-Y. Yin, "Prediction of higher heating values of biomass from proximate and ultimate analyses", Fuel, vol.90, pp.1128-1132, 2011.

[6] A.J. Callejón-Ferre, J. Carreño-Sánchez, F.J. SuárezMedina, J. Pérez-Alonso, B. Velázquez-Martí, "Prediction models for higher heating value based on the structural analysis of the biomass of plant remains from the greenhouses of Almería (Spain)", Fuel, vol.116, pp.377387, 2014.

[7] M. Erol, H. Haykiri-Acma, S.Küçükbayrak, "Calorific value estimation of biomass from their proximate analyses data", Renew. Energy, vol.35, pp.170-173, 2010.

[8] D.R. Nhuchhen, P.A. Salam, "Estimation of higher heating value of biomass from proximate analysis: a new approach". Fuel, vol.99, pp.55-63, 2012.

[9] J. Shen, S.Zhu, X. Liu, H. Zhang, J. Tan, "The prediction of elemental composition of biomass based on proximate analysis". Energy Convers. Manag, vol.51, pp.983-987, 2010.

[10] T. Cordero, F. Marquez, J. Rodriguez-Mirasol, J.J. Rodriguez, "Predicting heating values of lignocellulosics and carbonaceous materials from proximate analysis", Fuel, vol. 80, pp. 1567-1571, 2001.

[11] J. Parikha, S.A. Channiwalab, G.K. Ghosalc, "A correlation for calculating HHV from proximate analysis of solid fuels", Fuel, vol. 84, pp. 487-494, 2005.

[12] A.J. Callejón-Ferre, B. Velázquez-Martí, J.A. LópezMartínez, F. Manzano-Agugliaro, "Greenhouse crop residues: Energy potential and models for the prediction of their higher heating value", Renewable and Sustainable Energy Reviews, vol.15, pp. 948-955, 2011.

[13] ASTM-E 872. Volatile matter in the analysis of particulate wood fuels. Annual Book of ASTM Standards; 1982.

[14] ASTM-E 1755. Ash in biomass. Annual Book of ASTM Standards; 1995. 